\title{
Adaptive Neuro-Fuzzy Based UPQC in A Distributed Power System for Enhancement of Power Quality \\ M.Pradeep ${ }^{1}$, V.Padmaja ${ }^{2}$, E. Himabindu ${ }^{3}$ \\ 1,2,3 Geethanjali College of Engineering and Technology, \\ Cheeryal (V), Keesara (M), Medchal Dist, Telangana (INDIA)-501301 \\ Email: ${ }^{1}$ pradeep.mrtgpower@gmail.com, ${ }^{2}$ padmajavoleti08@gmail.com, ${ }^{3}$ himabindusrinivas2015@gmail.com
}

Received: 20 ${ }^{\text {th }}$ December 2017, Accepted: 20th January 2018, Published: 28th February 2018

\begin{abstract}
The power quality problems during distribution of power are mainly occurs due to transient distortions in the line voltage like harmonics, flicker, sags and swells. These power quality issues can cause damage of equipment, losses in power transfer or even can lead system towards instability. To alleviate these complications, ANFIS based UPQC is to be proposed. The object of this work is to develop the power quality all over and done with a new unified grid-connected inverter-based distributed power system by using ANFIS-UPQC. In this paper ANFIS based UPQC (ANFIS-UPQC) is being used as a Facts controller to mitigate together current \& voltage distortions at the consumer end of Distribution system. The concert of ANFIS-UPQC has very precise dynamic response by means of a very simple design of control circuit. This paper shows validation of ANFIS based UPQC and Results are compared with UPQC by means of hysteresis control Band by means of PI controller and improvements are observed. The ANFIS-UPQC reduces the harmonics at highly accepted level compared to PI Controller based UPQC. The simulation results, carried away by MATLAB/Simulink, shows that ANFIS-UPQC has a less THD and the output voltage/Current profiles are improved compared to PID Controller based UPQC.
\end{abstract}

Key words: Power Quality (PQ), UPQC, PI Controller, ANFIS, MATLAB/SIMULINK

\section{Introduction}

It's always a challenge to distribute the electric power without loss and it is necessary to retain the power quality within the limits. For achieving this, one of the newly developed Facts controllers is UPQC. It's a Facts device that consists of end-to-end connected two 3- $\phi$ ACTIVE POWER FILTERS (APFs) i.e. series and shunt inverters with a common DC-link. The shunt inverter of UPQC acts as a CSI for injecting current from end to end of a transformer in parallel, while the series inverter acts as a VSI for feeding voltage across a transformer in series. PCC can be extremely distorted; also the changes in highly rated load linked to PCC may result into voltage distortions on the PCC has been discussed [2]-[3]. Here, using of UPQC at PCC is an effective approach to care for the distribution system from sensitive loads. UPQC is a flexible device that can compensate nearly all power quality issues such as voltage sags/swell, voltage distortions, current distortions etc. The effect of sags can be less destructive than swells. For example, the high voltage during swell condition may cause insulation damage or breakdown in components or equipments. Due to unexpected changes of line current in the source impedance, voltage sag/swells takes place in the distributed system. The main aim is to keep the load bus voltage to be sinusoidal and the chief concern is the flow of active \& reactive power in this situation. It shows a vital role to choose the KVA ratings of both APFs. Among latest technical options available to enhance power quality, UPQC has set up more promising for compensate of current/voltage harmonics at the same time. As per literature review, application of UPQC for alleviation of voltage/current harmonics has been presented. It is normally constituted with two voltage source converters connected back to back through a DC-interface capacitor.

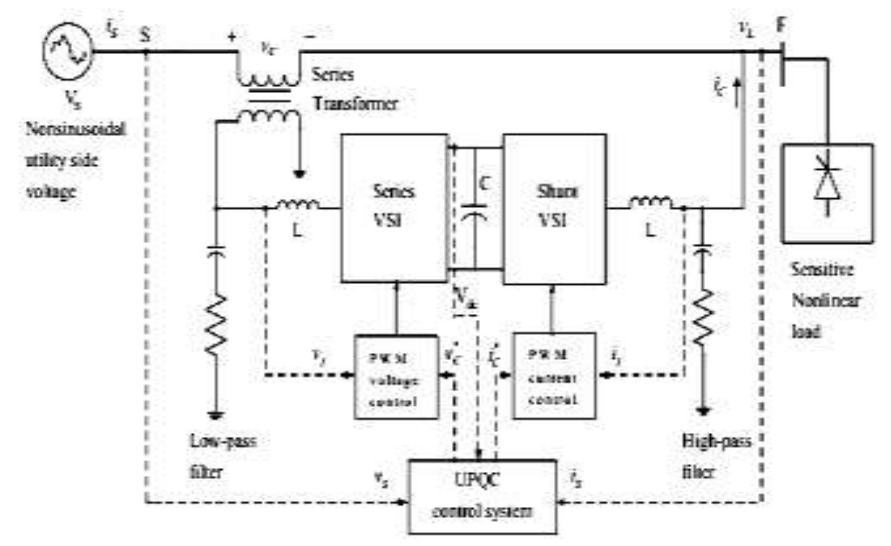

Fig.1. Basic Arrangement of UPQC

\section{Control Methods}

UPQC basically incorporates three sections: The series APF, shunt APF and energy storage capacitors. Both are couples together through the DC-interface capacitors. Series APF associated with grid and load by coupling transformer is predominantly used to modify the load voltage magnitude and mitigate the power supply voltage sag/swell in the controlled VSI mode. Shunt APF associated to the load end is used to steadiness load currents. 


\section{Artificial Neural Network Based Fuzzy Interference Systems}

A neuro fuzzy structure is a fuzzy structure that practices a derived learning algorithm or stimulated by the theory of neural networks to determine its factors (fuzzy set and fuzzy rules) by handling data models. NFC is the arrangement of Fuzzy Inference System (FIS) and NN. The fuzzy logic is activated permitting to the fuzzy rule and $\mathrm{NN}$ is accomplished based on the training data. The neural network formation data set is generated by fuzzy rules. The NFC function is clarified in the following section.

\section{A. Fuzzy logic controller}

FLC is based on fuzzy logic -a mathematical system that analyzes along input values in terms of logical variables that take on continuous values between Zeros and ones. FLC give the linguistic approaches control adaptation from practiced familiarity in automatic control schemes. In the fuzzy control scheme, the operation of controller is mainly constructed on fuzzy rules, which are created using fuzzy set theory. Fuzzy controller plays an important role in the compensation of PQ problem. The steps involved in fuzzy controller are fuzzification, decision making and defuzzification. Fuzzification is the method of changing the crisp value into fuzzy value.

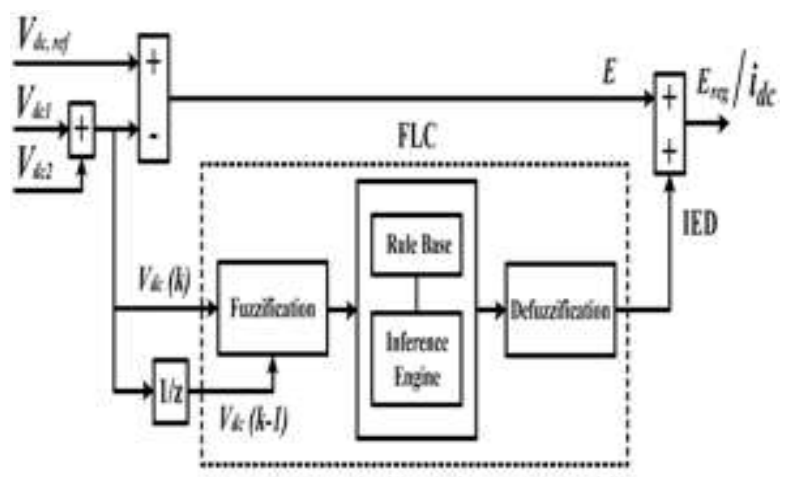

Fig.2.Proposed DC-Interfac capacitor voltage regulation control structure

\section{Fuzzification strategy}

- Data base building

- Rule base elaboration

- Interface machine elaboration

- Defuzification strategy

Also, outline of FLC can give keen both small signal and large signal dynamic execution at same time, which is unlikely with linear control method. The advancement of fuzzy logic approach here is constrained to the plan and structure of the controller. The contributions of FLC are characterized as the voltage blunder, and change of error. Fuzzy sets are characterized for each information and output variable. There are five fuzzy levels which described in Rule table. The enrollment capacities for input and output factors are triangular. The min-max technique interface engine is used. The fuzzy technique utilized as a part of this FLC is focal point of territory. The entire arrangement of control rules is appeared in Table.1. Each of the 25 control rules speaks to the coveted controller reaction to a specific circumstance. Figureestablishes the square chart of a FLC.

\section{Error}

\begin{tabular}{|c|c|c|c|c|c|}
\hline & NB & NS & ZE & PS & PB \\
\hline NB & NB & NB & NM & NB & NM \\
\hline NS & NB & NB & NS & ZE & NM \\
\hline ZE & NS & ZE & ZE & ZE & PS \\
\hline PS & PM & ZE & PS & PB & PB \\
\hline PB & PB & PB & PM & PB & PB \\
\hline
\end{tabular}

Table.1. Control Rules

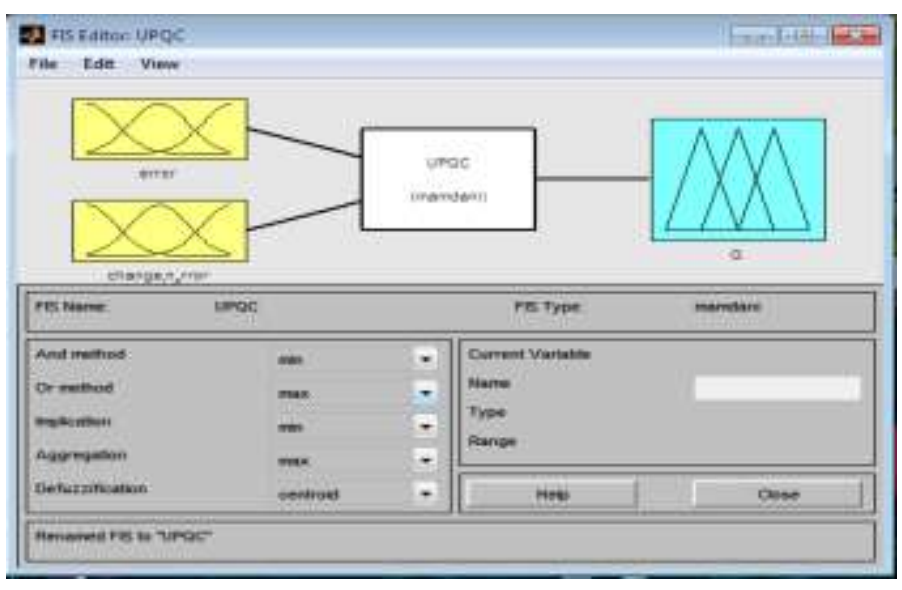

Fig.3.Fuzzy inference Systems

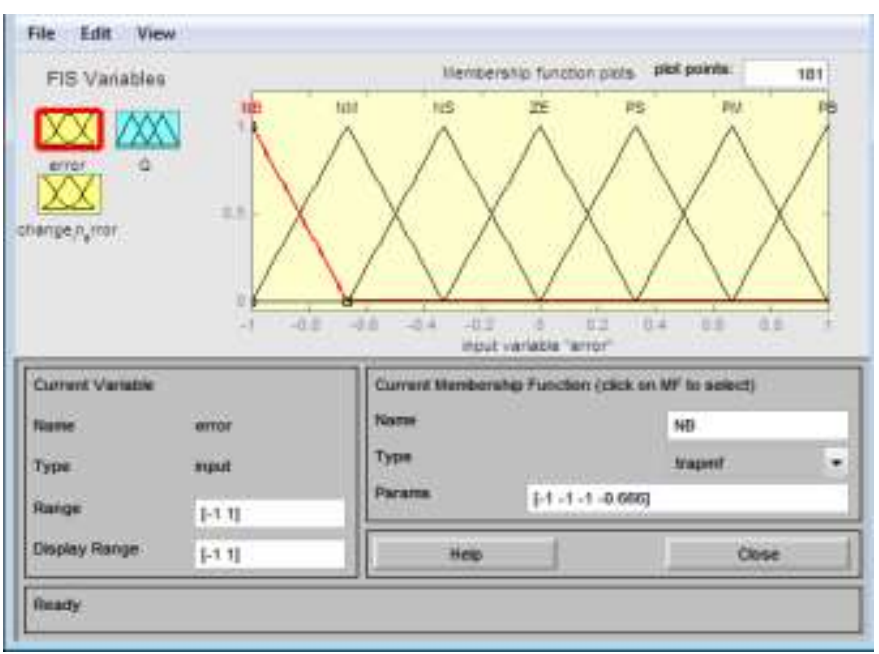

Fig.4.Membership functions for Error. 


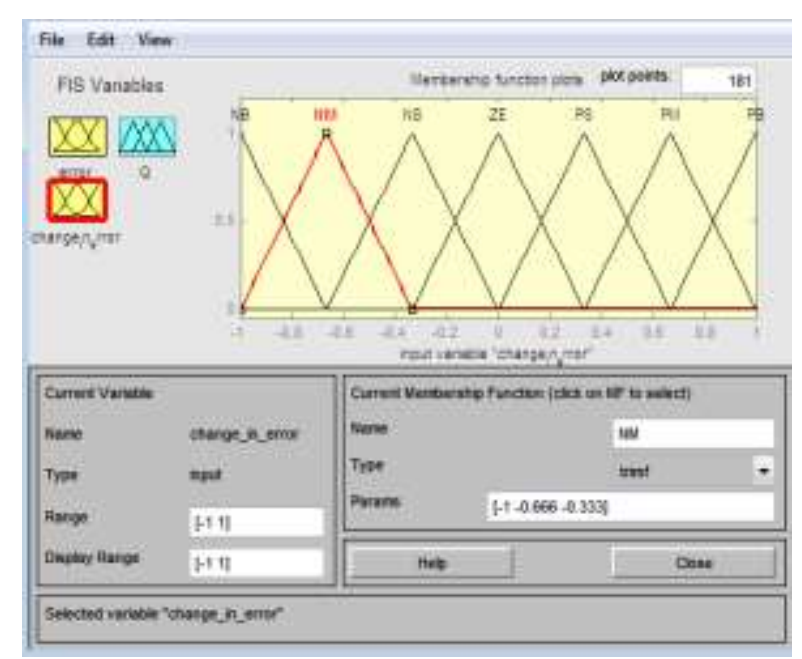

Fig.5.Membership functions for Change in Error

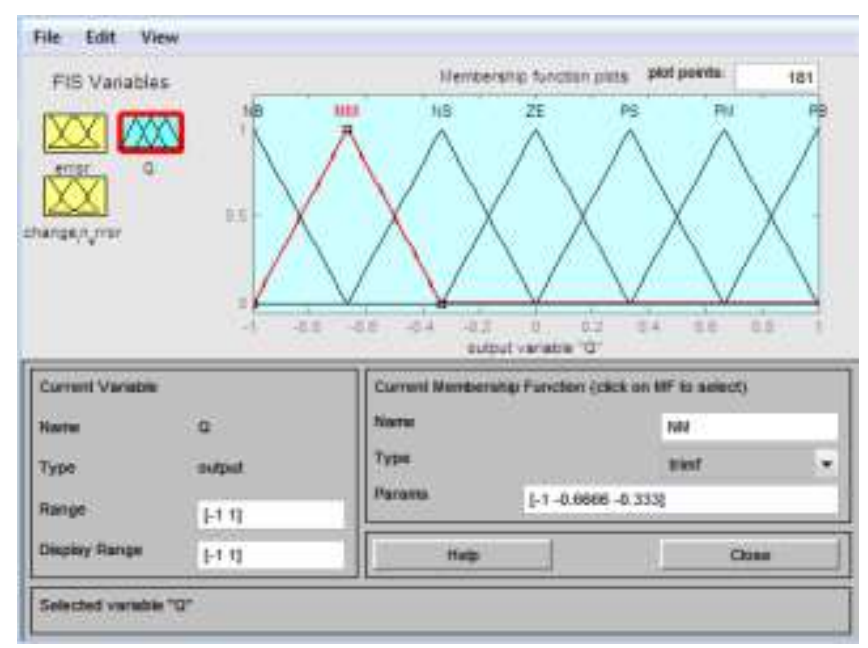

Fig.6. Membership functions for Power Loss.

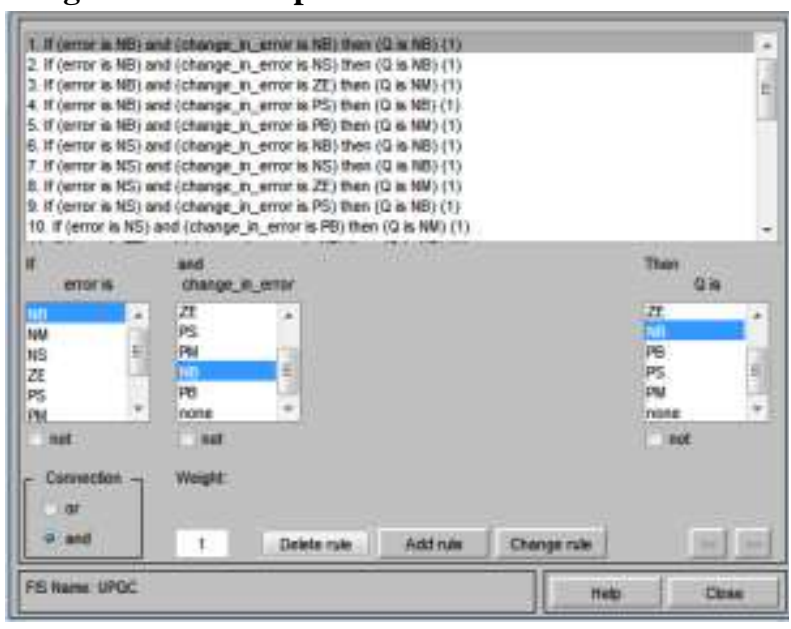

Fig.7. Rule base table.

\section{B. DESIGNING \& TRAINING OF ANN}

An Artificial neural Network (ANN), regularly called a "Neural Network" (NN), is a systematic model or computational model in view of natural neural systems. It comprises of an interrelated collecting of artificial neurons and procedures data utilizing a connectionist way to deal with calculation. By and large an ANN is a versatile framework that progressions its structure in light of outside or interior data that moves through the system along with the learning stage. In more functional terms neural systems are non-direct measurable information demonstrating apparatuses. They can be utilized to display complex connections amongst information sources and yields or to discover designs in information. $\mathrm{NN}$ is a manmade brainpower method that is utilized for producing preparing informational collection and testing the connected info information. A sustain forward sort $\mathrm{NN}$ is utilized for the proposed strategy. Ordinarily, the NN comprise of three layers: input layer, shrouded layer and yield layer. Here, the blunder, change of mistake, and the managed regulated voltages are meant as $\mathrm{Ve}, \mathrm{V} \Delta \mathrm{e}$, and $\mathrm{V}_{\mathrm{DCNN}}$ respectively. The structure of the $\mathrm{NN}$ is described as

follows.

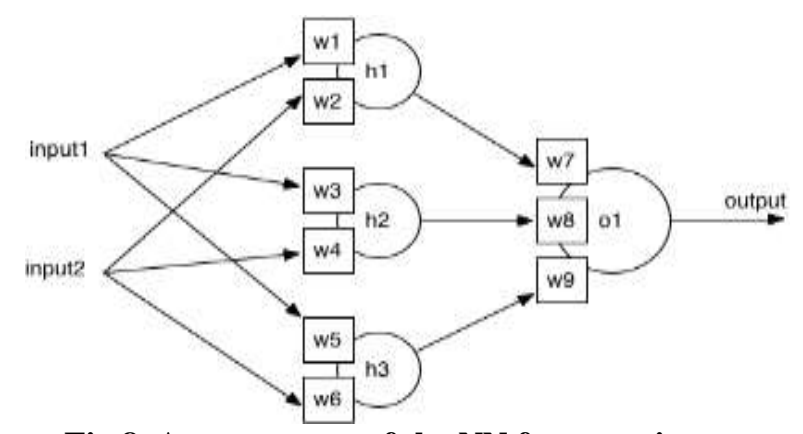

Fig.8. Arrangement of the NN for capacitor Voltage Regulation.

In Figure-8., the input layer, hidden layer and output layer of the system are (H11, H12), (H21, H22... .. $\mathrm{H} 2 \mathrm{~N}$ ) and $\mathrm{H} 31$ individually. The heaviness of the input layer to hidden layer is indicated asw11, w 12 , $w 1 N, w 21, w 22$, and $w 2 N$. The weight of the hidden layer to output layer is meant as w 211, w221, w2N1. Here, the Back Propagation (BP) preparing calculation is utilized for preparing the system. Figure-9 Shows the Proposed System NN Structure. 


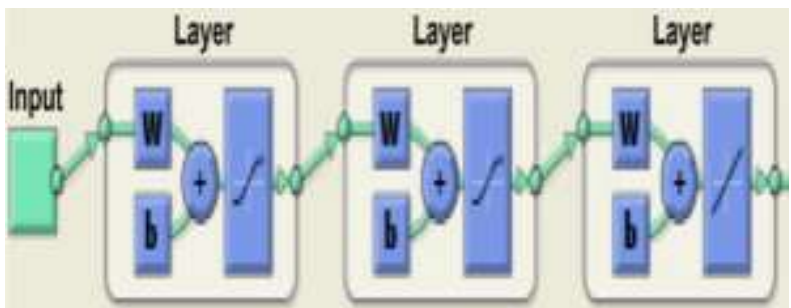

Fig.9. Proposed System NN structure.

ANFIS controller, which turns into an incorporated technique for approach for the control purposes and yields brilliant outcomes, which is the feature of this paper [1]. In the outlined ANFIS scheme, neural system methods are utilized to choose an appropriate control base, which is accomplished utilizing the back proliferation calculation. This incorporated approach enhances the framework execution, costadequacy, effectiveness, dynamism, and unwavering quality of the planned controller. ANFIS controller is utilized to decrease the power mistake to zero.

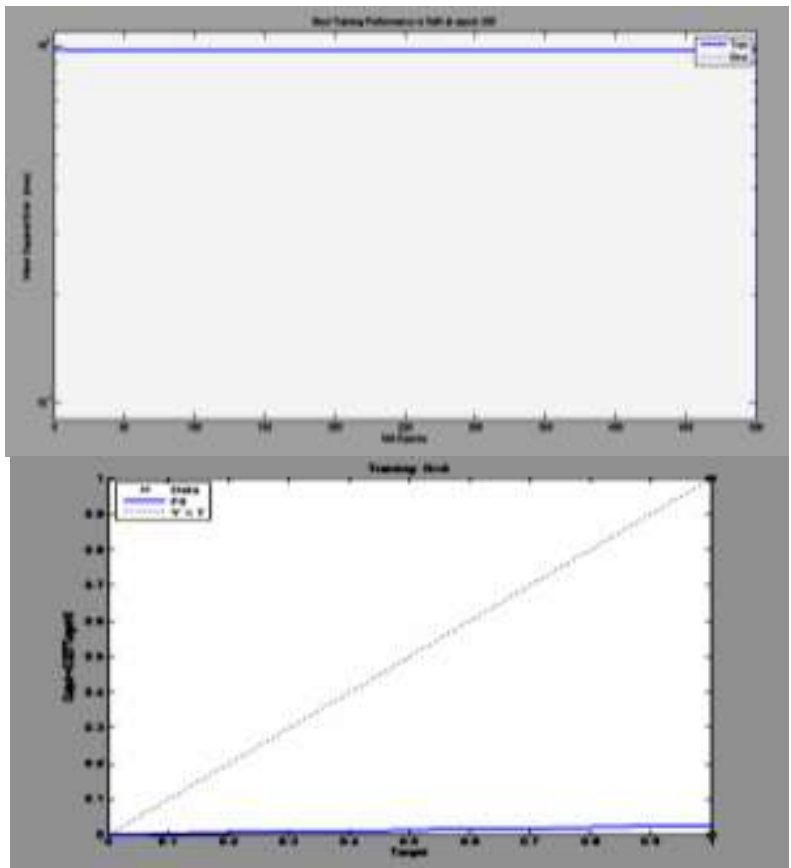

Fig.10. NN Performance Plots (i) Regression Analysis, (ii) Network Validation performance and (iii) Training State.

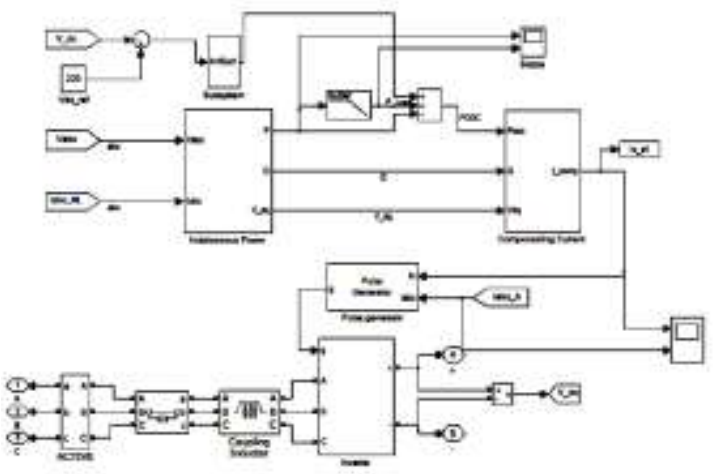

Fig.13.Simulation Adaptive NFIS based Shunt APF.

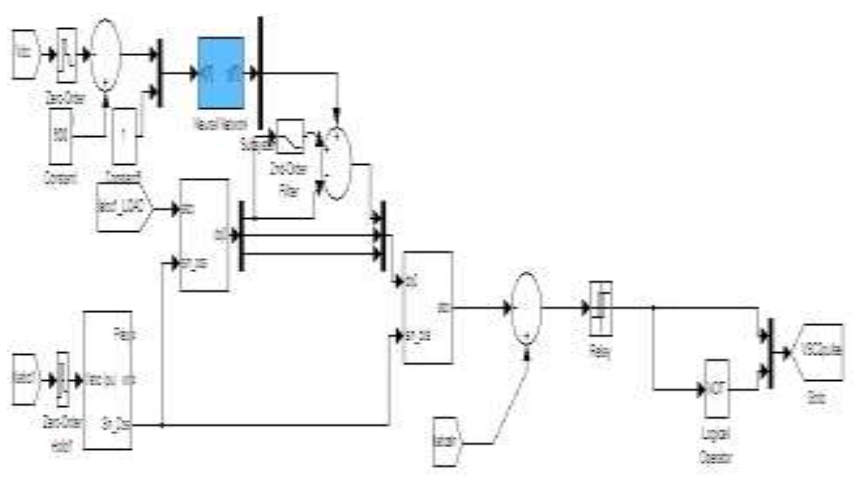

Fig.11.simulation Neural network

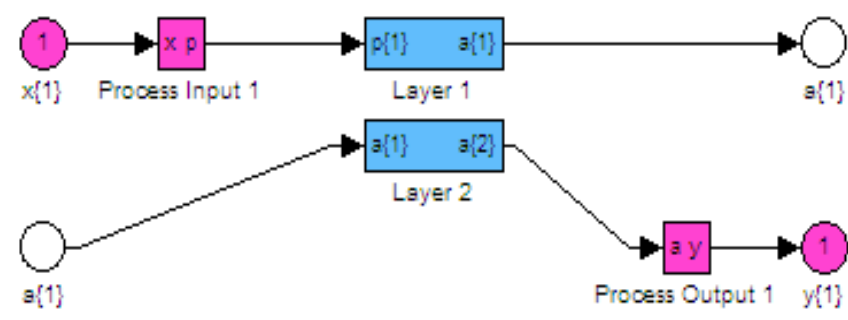

Fig.12.Simulation of proposed NN structure

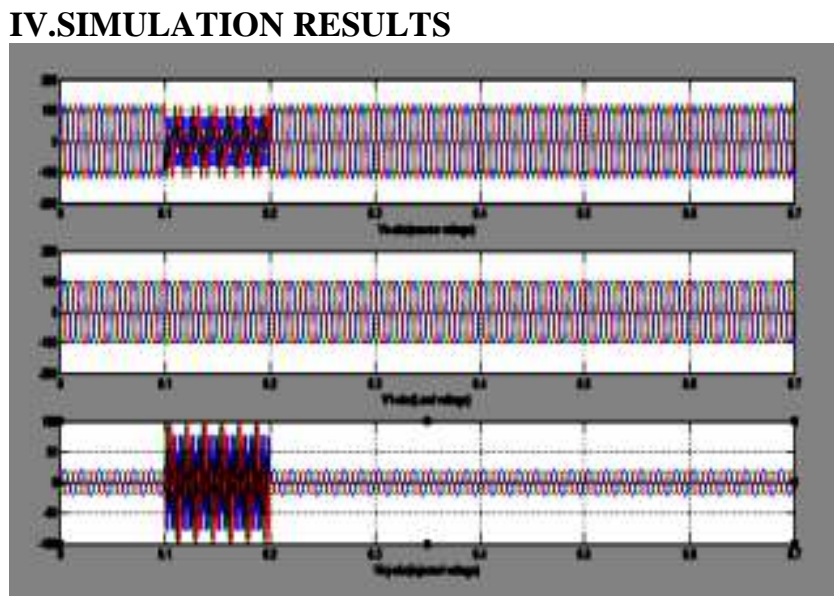

Fig.14. Simulation result of $\left(v_{S \_a b c}\right),\left(v_{L \_a b c}\right)$ and (Vinj_abc) during swell condition

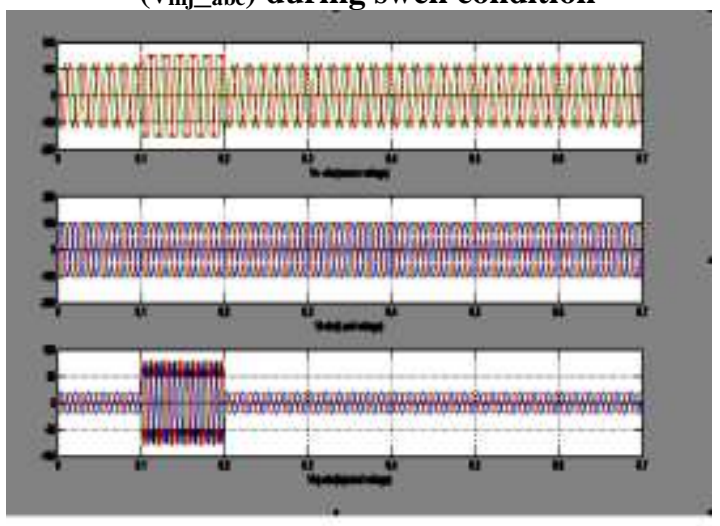


Fig.15. Simulation result of $\left(V_{S \_a b c}\right),\left(V_{L \_} a b c\right)$ and $\left(V_{\text {inj_abc }}\right)$ during sag condition

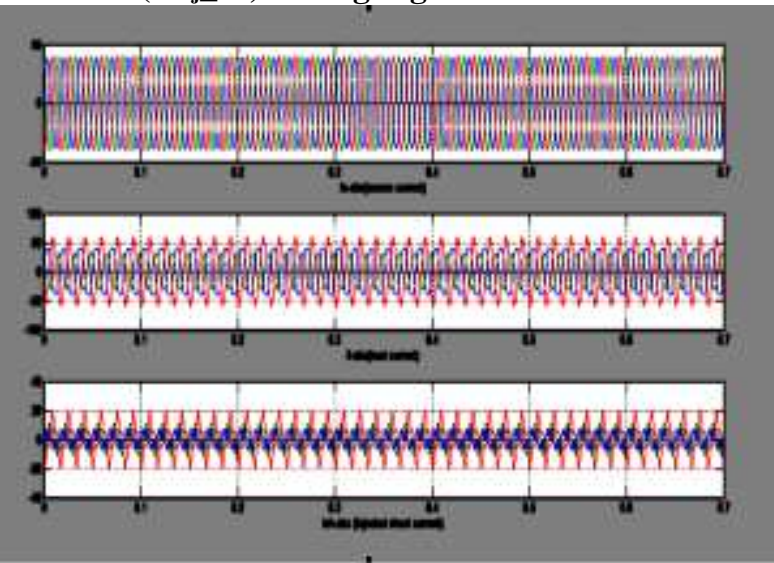

Fig.16. Simulation results of $\left(i_{S \_a b c}\right),\left(i_{L \_} a b c\right)$ and $(i$ Sh_abc $)$.

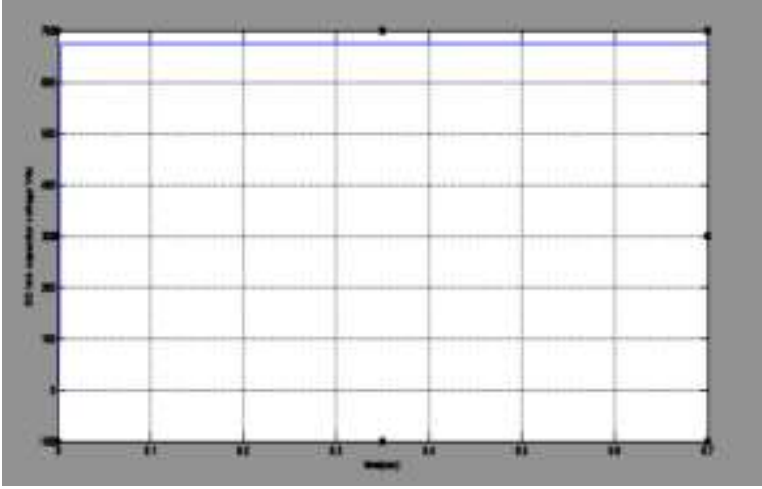

Fig.17.Simulation results of $\left(V_{\mathrm{dc}}\right)$

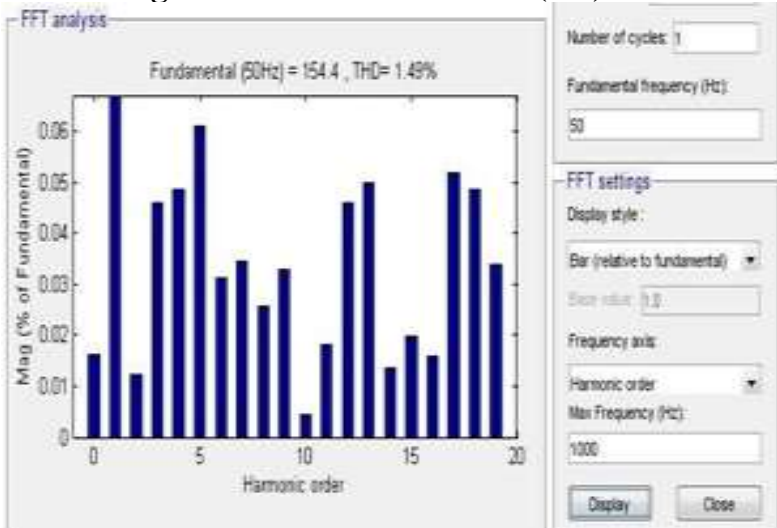

Fig.18. THD for $\left(V_{\text {inj_abc }}\right)$

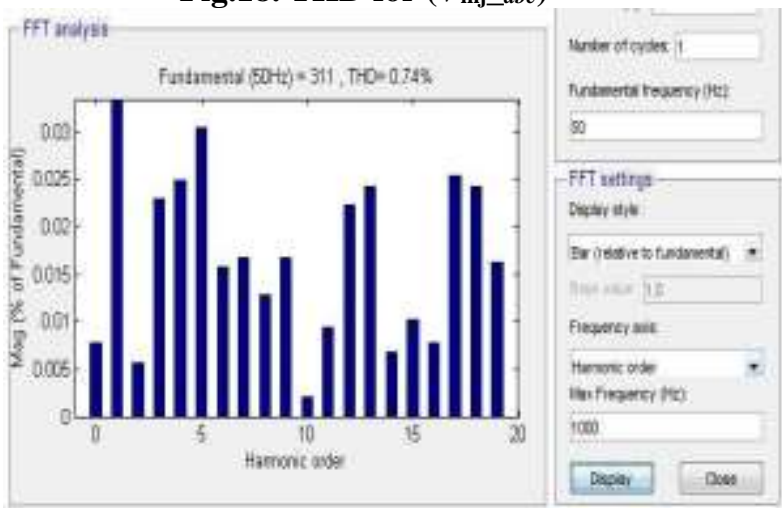

Fig19.THD for $\left(V_{S \_a b c}\right)$

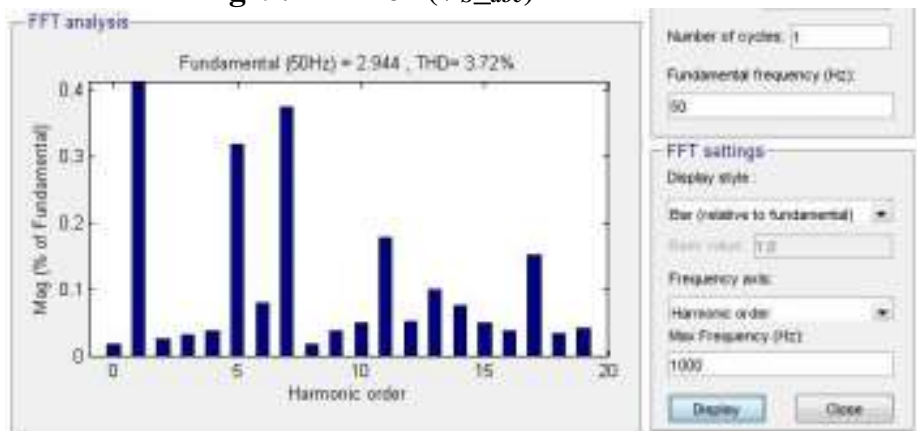

Fig.20.THD for $\left(i_{S \_a b c}\right)$
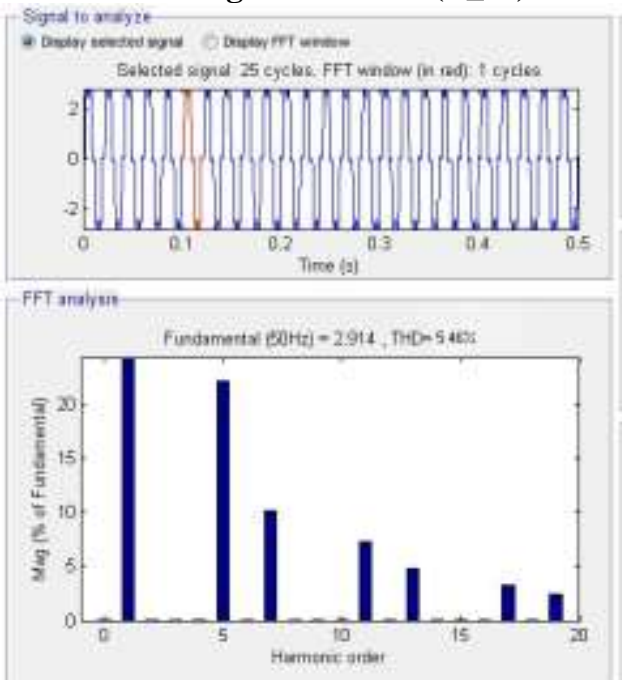

Fig.2. THD for $i_{L \_} a b c$.

Table-I: THD Results

\begin{tabular}{|c|l|l|l|l|}
\hline Results & $\begin{array}{l}\text { THD } \\
\text { for } \\
\text { Grid } \\
\text { Curre } \\
\text { nt }\end{array}$ & $\begin{array}{l}\text { THD } \\
\text { For } \\
\text { Grid } \\
\text { Voltag } \\
\text { e }\end{array}$ & $\begin{array}{l}\text { THD } \\
\text { for } \\
\text { Load } \\
\text { Curre } \\
\text { nt }\end{array}$ & $\begin{array}{l}\text { THD } \\
\text { For } \\
\text { Injecte } \\
\text { d } \\
\text { Voltag } \\
\text { e }\end{array}$ \\
\hline $\begin{array}{c}\text { With } \\
\text { ANFIS }\end{array}$ & $3.72 \%$ & $0.74 \%$ & $5.46 \%$ & $1.49 \%$ \\
\hline $\begin{array}{c}\text { Witho } \\
\text { ut } \\
\text { ANFIS }\end{array}$ & $10.45 \%$ & $5.3 \%$ & $15.45 \%$ & $4.43 \%$ \\
\hline
\end{tabular}

\section{Conclusion}

This paper is for the most part dedicated to the investigation of Power Quality issues and its remuneration with Unified power quality conditioner (UPQC). Results obtained from this examination give helpful data with respect to the conduct of various controllers used for control quality change associated with grid. The controllers for the most part utilized for control quality change from PI to Adaptive neuro fuzzy controller (ANFIS). 
The advancement comes about validate that the UPQC with PI Controller Compensates $85 \%$ of voltage transient, While UPQC with Adaptive neuro fuzzy controller (ANFIS) Compensates $98 \%$ of voltage transient. Thus when contrasted with the reaction acquired with PI Controller, Adaptive neuro fuzzy controller (ANFIS) based controller have awesome favorable position of flexibility.

\section{References}

1. Vadirajacharya G. Kinhal, PromodAgarwal, and HariOamGupta (2011), Senior Member, IEEE "The Search for Unified Unified Energy Performance Based on Neural Networks".

2. Ruiye Liu, Ning Xia, Wang Xiaonan "Research on Fuzzy-PID Control in Unitary Conditioner".

3. R.H.Lasseter and P.Paigi, "Microgrid: A Conceptual Solution", in Proc.IEEE Power Electron Spec.conf., Jun.2004, 4285-4290.

4. A. K. Gautam *, S.P. Singh *, J.P. Pandey *, R.P. Payasi * and Nikhil Gupta. "Quality of Performance for Energy Quality to Improve Energy Quality in Distribution System" IEEE Uttar Pradesh International Conference on Electrical Engineering, Computer and Electronics (UPCON)-2016

5. Quoc-Nam Trinh, Hong-Hee Lee "Best Performance of Unified Energy Quality Conditioner with Improved Resonance Control Strategy" Published in Generation, Transmission and Distribution IET. ISSN 17518687, 2014.

6. MihirHembram, Ayan Kumar Tudu, "Mitigating Power Quality Problems by Using Unique Energy Conditioner (UPQC)" IEEE Transactions on Power Quality 2015.

7. UdayKishanRenduchintala, Chengzong Pang "UPQC driver neuro-fuzzy base to improve power quality in the microgrid system" "IEEE Transactions on Power Quality, 2016.

8. Hideaki Fujita, Hirofumi Akagi, "A Unified Power Quality Conditioner: Integrating Active Series Filters and Shunt" IEEE Transactions on POWER ELECTRONICS, VOL. 13, NO. March 2, 1998

9. GuJianjun, XuDianguo, Liu Hankui, and Gong Maozhong

"Unified Energy Quality Conditioner (UPQC): Principle, Control and Application" PCCOsaka 2002

10. Víctor M. Moreno, Alberto Pigazo, Marco Antonio Liserre and Dell'Aquila "Unified Power Quality Conditioner (UPQC) with Sauces and Surge Compensation Capability" RE \& PQJ, Vol. 1, No. 6, March 2008

11. Anil Bharti, RajatVarshney, DrS.K.Srivastva "An IP Based Unified Power Quality Conditioner Controller" IJARCSSE Volume 2, Issue 9, September 2012
12. W. AnaghaWaghadkar, M. R Salodkar "Improved feeding quality using Fuzzy Logic based UPQC "IJAREEIE, Vol. 5, Issue 6, June 2016 